HortSCIENCE 27(5):432-434. 1992.

\title{
Repeated Mechanical Stress from Leaf Cuvette Influences Leaf Gas Exchange
}

\author{
Thomas E. Marler ${ }^{1}$ and Michael V. Mickelbart \\ Fairchild Tropical Garden, 11935 Old Cutler Road, Miami, FL 33156
}

Additional index words Annona squamosa, Averrhoa carambola, avocado, carambola, hibiscus, Hibiscus rosa-sinensis, Mangifera indica, mango, Persea americana, sugar

apple

Abstract. Long-term effects on stomatal conductance of mechanical stress from repeated clamping of a porometer leaf cuvette to laminae of avocado (Persea americana Miller), carambola (Averrhoa carambolu L.), hibiscus (Hibiscus rosa-sinensis L.), mango (Mangifera indica L.), and sugar apple (Annona squamosa L.) plants were determined under glasshouse conditions. Following 10 weeks of applying the mechanical stimulus seven times during every 4th day to mature leaves, stomatal conductance was lower than for untreated leaves of all species except mango. Similarly, following 10.5 weeks of applying the stimulus one time every 4th day to expanding leaves of avocado, carambola, hibiscus, and sugar apple, stomatal conductance was lower than for untreated leaves of the same age in all species except hibiscus. Carambola and sugar apple were more sensitive to the mechanical stress than the other species. Thus, the indirect effect of leaf chamber clamping on gas exchange should be known before any conclusions are formulated regarding environmental, cultural, or genetic effects on gas exchange. Random leaf samples from a canopy instead of measurements on a fixed set of leaves may be more appropriate for repeated determinations of leaf gas exchange on a set of plants.

Various leaf chambers are used in foliar gas-exchange research, with a basic assumption that leaf physiology is not affected by inserting the leaves for measurements. Chambers are designed such that the effect on leaf environment during measurement is minimal (Long and Hallgren, 1987). However, many gas-exchange studies involve repeated measurements over time. Representative leaves within a canopy commonly are chosen at the onset of a study, with each measurement being made on the same set of leaves over time. This methodology assumes that repeated leaf insertion into cuvettes and the resulting mechanical stress have minimal effects on leaf physiology.

Mechanical stress administered in various ways has influenced plant growth and development. Stress has been applied as rubbing or flexing of leaves or stems, shaking,

Received for publication 28 May 1991. Accepted for publication 2 Dec. 1991. The cost of publishing this paper was defrayed in part by the payment of page charges. Under postal regulations, this paper therefore must be hereby marked advertisement solely to indicate this fact.

'Present address: College of Agriculture and Life Sciences, Univ. of Guam, UOG Station, Mangilao, Guam 96923. stroking or brushing, water spray, or artificial wind (e.g., see Biddington, 1986; Latimer, 1991). Responses to mechanical stress have included altered whole-plant growth, organ development, leaf gas exchange, stem flexibility, and hormone metabolism. Significant responses have been obtained with the stress duration as short as $10 \mathrm{~s} \cdot \mathrm{day}^{-1}$ (Wheeler and Salisbury, 1979).

The ADC Parkinson leaf chambers (Analytical Development Corp., Hoddesdon, U.K.) and the LI-COR LI-1600 series and LI-6000 series chambers (LI-COR, Lincoln, Neb.) are commercially available for gasexchange research. These chambers apply a mechanical stress to portions of leaf laminae during gas-exchange measurements. The purpose of this study was to determine the long-term effects on gas-exchange caused by repeated loading and unloading of laminae of a range of species into a leaf chamber. The LI-COR LI-1600 series leaf chamber was chosen for the study.

Species chosen were avocado, carambola, hibiscus, mango, and sugar apple. 'Brooks Late' avocado fruits were harvested on 19 Jan. 1990. Seeds were extracted and planted individually into 2.6-liter (15-cm diameter) containers. 'Golden Star' carambola fruits were harvested on 5 Jan. 1990. Seeds were 
Table 1. Stomatal conductance of five tropical species as influenced by repeated mechanical stress from porometer leaf chamber. Treated leaves were inserted into the leaf chamber seven times every 4th day from 16 July-25 Sept. 1990. Data were collected during 26-28 Sept. Means represent a total of 36 observations.

\begin{tabular}{lccc}
\hline \hline Species & Treatment & $\begin{array}{c}\text { Stomatal conductance } \\
\left(\mathrm{mmol} \cdot \mathrm{m}^{-2} \cdot \mathrm{s}^{-1}\right)\end{array}$ & $\begin{array}{c}\text { Percentage of } \\
\text { control }\end{array}$ \\
\hline Avocado & Control & 146 & 72 \\
Carambola & Treated & $105^{* * *}$ & 44 \\
Hibiscus & Control & 166 & 67 \\
Mango & Treated & $73^{* * *}$ & 67 \\
& Control & 251 & 91 \\
Sugar apple & Treated & $168^{* * *}$ & 51 \\
& Control & 195 & 51 \\
\hline
\end{tabular}

NS,***Means separation within each species nonsignificant or significant at $P=0.0001$, respectively.

Table 2. Stomatal conductance of four tropical species as influenced by repeated mechanical stress from porometer leaf chamber. Treated expanding leaves were inserted into the leaf chamber one time every 4th day from 16 July-28 Sept. 1990. Data were collected 29 Sept.-1 Oct. Means represent a total of 36 observations.

\begin{tabular}{lccc}
\hline \hline Species & Treatment & $\begin{array}{c}\text { Stomatal conductance } \\
\left(\mathrm{mmol}^{-2} \cdot \mathrm{s}^{-1}\right)\end{array}$ & $\begin{array}{c}\text { Percentage of } \\
\text { control }\end{array}$ \\
\hline Avocado & Control & 152 & \\
& Treated & $124^{* *}$ & 82 \\
Carambola & Control & 184 & 37 \\
& Treated & $68^{* * *}$ & 102 \\
Hibiscus & Control & 249 & 76 \\
Sugar apple & Treated & $254^{\mathrm{NS}}$ & 72 \\
& Control & $146^{* *}$ & 76 \\
\hline
\end{tabular}

Ns,****** Means separation within each species nonsignificant or significant at $P=0.001$ or 0.0001 , respectively.

extracted and planted into 3.1-liter clay pots. Seedlings were transplanted into individual 1-liter containers on 20 Mar. and into 2.6liter containers on 28 June. Semi-hardwood cuttings of 'Anderson's Crepe' hibiscus were taken on 24 Mar. 1990, quick-dipped in 2500 ppm IBA, stuck in perlite, and rooted under intermittent mist. Rooted cuttings were transplanted into individual 2.6-liter containers on 25 Apr. Fruits of 'Turpentine' mango were harvested on 18 May 1990, seeds extracted, and planted individually into 2.6liter containers. Sugar apple seeds were obtained commercially and planted on 26 May 1989 in 3.1-liter clay pots. Seedlings were transplanted into individual 2.6-liter containers on 24 Jan. 1990. Container medium consisted of equal volumes of shredded pine bark : silica sand : perlite : peat.

Each group of plants was placed on raised benches in a glasshouse $(50 \%$ whitewash shade). Plants were hand-watered to pot capacity daily. All plant material was grown with a top dressing of $5 \mathrm{~g} 12 \mathrm{~N}-2.6 \mathrm{P}-6.6 \mathrm{~K}$ $2.4 \mathrm{Mg}-1.5 \mathrm{Mn}-0.1 \mathrm{Cu}-0.1 \mathrm{Zn}-1.3 \mathrm{Fe}$ granular fertilizer and a $125-\mathrm{ml}$ drench of $2.5 \mathrm{~mm}$ $\mathrm{Fe}$ (as Fe-EDDHA) solution per container every 2 months. The last fertilization before experimental treatment application was 10 June. Plants were chosen from the group of each species for two sets of studies.

Repeated diurnal measurements. Six uniform plants from each species were chosen to study the influence of repeated diurnal loading and unloading of leaves on gas exchange. Mango plants were placed pot-topot, and the other four species were placed
$30 \times 40 \mathrm{~cm}$ on center. One recently expanded mature leaf was tagged on each plant. Every 4th day, beginning 16 July 1990, tagged leaves were inserted into the chamber for 3 to $5 \mathrm{sec}$ at 2 -h intervals throughout the photoperiod (total of seven times). All species had simple leaves, except carambola; the third or fourth leaflet from the terminal on each tagged leaf was used for this species. Treatments were imposed until 25 Sept. for a total of 10 weeks. Maxima during the experimental period ranged from 29 to $37 \mathrm{C}$ (mean of $34 \mathrm{C}$ ) and minima ranged from 22 to $26 \mathrm{C}$ (mean of 24C). Maximum relative humidity (RH) ranged from $85 \%$ to $94 \%$ (mean of $91 \%$ ), and minimum RH ranged from $50 \%$ to $69 \%$ (mean of 57\%). Temperature and RH data were recorded by hygrothermograph (WEATHERtronics 5020, Qualimetrics, Sacramento, Calif.).

Stomata1 conductance of the treated lamina and an untreated leaf of similar age was measured on each plant with the porometer, beginning at $1000 \mathrm{HR}$ on 26 Sept. This process was repeated at $1300 \mathrm{HR}$ with a different untreated leaf on each plant. Measurements were repeated on 27 and 28 Sept. for a total of six pairs per plant, each time with the same treated leaf and a different, previously untreated leaf. Three of the untreated leaves were toward the apex, and three toward the base relative to the treated leaf. Conditions during the six periods throughout which measurements were being made were: air at 28 to $33 \mathrm{C} ; 415$ to $510 \mu \mathrm{mol} \cdot \mathrm{m}^{-2} \cdot \mathrm{s}^{-1} \mathrm{pho}-$ tosynthetic photon flux (PPF); and $58 \%$ to $70 \% \mathrm{RH}$
Expanding leaf measurements. Six uniform plants per species (except mango) were chosen for a second set of experiments. An unfolding leaf or leaflet was tagged on each plant, and every 4th day, beginning 16 July, these lamina were carefully placed in the leaf chamber for 3 to $5 \mathrm{sec}$ one time during midday. Treatments were imposed until 28 Sept., for a total of 10.5 weeks. Greenhouse conditions during the development period of this second study and methods for obtaining final measurements were as previously described. Conditions during the six actual periods of measurement from 29 Sept. to 1 Oct. were: air at 26 to $32 \mathrm{C} ; 364$ to $455 \mu \mathrm{mol} \cdot \mathrm{m}^{-2} \cdot \mathrm{s}^{-1}$ PPF, and $72 \%$ to $86 \%$ RH.

These two methods of administering mechanical stress not only simulated procedures commonly used in gas-exchange studies with horticultural crops, but also applied the mechanical stress at two dose levels.

Conductance data for each species were analyzed separately as a three-factor factorial analysis of variance in a completely randomized design. Sources of variation in each of the experiments included days of measurements $(n=3)$, time of day during which measurements were made $(n=2)$, and treatments $(\mathrm{n}=2)$.

Repeated diurnal mechanical stress from the cuvette reduced stomatal conductance of avocado, carambola, hibiscus, and sugar apple but did not influence that of mango (Table 1). Day or time of day during which measurements were made did not influence gas exchange, and there were no interactions between the main effects. Stomatal conductance of sugar apple and carambola was reduced more by mechanical stress than was that of the other species.

Stressing of the expanding leaves one time every 4th day reduced stomatal conductance of avocado, carambola, and sugar apple leaves compared with controls (Table 2). No interactions occurred, and measurement period did not influence gas exchange. Stomata1 conductance of hibiscus leaves was not influenced by the stress administered during leaf development. The magnitude of reduction in stomatal conductance depended on species, with carambola being affected most severely.

The goal of most gas-exchange studies with horticultural crops is to determine a response to stress, leaf age, or some other factor. As a result, the method of data collection should not itself affect gas exchange. These data indicate that repeated loading of laminae into leaf cuvettes may influence leaf gas exchange in some species. As a result, a random sample of leaves from a canopy at each measurement period may be a more accurate method of data collection. Certainly, any use of repeated measurements on the same set of leaves should be preceded by an investigation to determine effects of the leaf chamber on stomatal physiology. This investigation must be conducted under the same environmental and genetic conditions as the planned research.

A correlation between treatment dose level and plant response has been shown for seis- 
mic (Heuchert and Mitchell, 1983; Mitchell et al., 1975) and thigmic (Braam and Davis, 1990; Jaffe, 1973) stresses. The reduction in stomatal conductance in the present study might have been more dramatic if mechanical stress from the leaf chamber had been maintained for $>60 \mathrm{sec}$ (normal for actual porometer measurements) instead of 3 to 5 sec.

In early work with porometers, Knight (1917) expressed some concern about stomatal reaction to handling and advised careful consideration of this possibility when using leaf cuvettes. A reduction in leaf gas exchange in response to long-term, repeated measurements may go undetected in some cases if the reduced values are within an expected range. For example, stomatal conductance of treated leaves for the four species included in Table 1 and the three species included in Table 2 that were significantly affected by the mechanical stress averaged $\approx 100 \mathrm{mmol} \cdot \mathrm{m}^{-2} \cdot \mathrm{s}^{-1}$. This is well within the expected range for evergreen woody plants (Korner et al., 1979).

Carambola was the most affected of the five species studied. Carambola is intolerant of windy conditions, and it long has been known that leaves of plants in the genus $A v$ errhoa are sensitive to touch (Darwin, 1896).

Altered leaf gas exchange has been reported for various mechanical stimuli. Photosynthesis, stomatal conductance, respiration, or transpiration has been affected by wind (Grace, 1974; Grace and Thompson, 1973; Martin and Clements, 1935; Todd et al., 1972), rubbing or handling (Audus, 1935; Godwin, 1935; Mitchell et al., 1977), or shaking (Mitchell et al., 1977; Pappas and Mitchell, 1985).

In conclusion, repeated mechanical stress from a leaf chamber reduced stomatal conductance of avocado, carambola, hibiscus, and sugar apple. The amount of reduction was species dependent. Use of a random sample of leaves within a canopy at each measurement period rather than repeated measurements on the same set of leaves may give more accurate determinations of gas exchange in studies requiring repeated measurements on a set of plants.

\section{Literature Cited}

Audus, L.J. 1935. Mechanical stimulation and respiration rate in the cherry laurel. New Phytol. 34:386-402.

Biddington, N.L. 1986. The effects of mechanically-induced stress in plants-a review. Plant Growth Regulat. 4:103-123.

Braam, J. and R.W. Davis. 1990. Rain-, wind-, and touch-induced expression of calmodulin and calmodulin-related genes in Arabidopsis. Cell 60:357-364.

Darwin, C. 1896. The power of movement in plants. Appleton \& Co., New York

Godwin, H. 1935. The effect of handling on the respiration of cherry laurel leaves. New Phytol. 34:403-406.

Grace, J. 1974. The effect of wind on grasses. I. Cuticular and stomatal transpiration. J. Expt. Bot. 25:542-551.

Grace, J. and J.R. Thompson. 1973. The after- effect of wind on the photosynthesis and transpiration of Festuca arundinacea. Physiol. Plant. 28:541-547.

Heuchert, J.C. and C.A. Mitchell. 1983. Inhibition of shoot growth in greenhouse-grown tomato by periodic gyratory shaking. J. Amer. Soc. Hort Sci. 108(5):795-800.

Jaffe. M.J. 1973. Thigmomorphogenesis: the response of plant growth and development to mechanical stimulation. Planta 114:143-157.

Knight, R.C. 1917. Recent work on transpiration. New Phytol. 16:127-139.

Korner, CH., J.A. Scheel, and H. Bauer. 1979. Maximum leaf diffusive conductance in vascular plants. Photosynthetica 13:45-82.

Latimer, J.G. 1991. Mechanical conditioning for control of growth and quality of vegetable transplants. HortScience 26(12):1456-1461.

Long, S.P. and J.E. Hallgren. 1987. Measurement of $\mathrm{CO}_{2}$ assimilation by plants in the field and the laboratory, p. 62-94. In: J. Coombs, D.O. Hall, S.P. Long, and J.M.O. Scurlock (eds.). Techniques in bioproductivity and photosynthesis. 2nd ed. Pergamon, New York.
Martin, E.V. and F.E. Clements. 1935. Studies of the effect of artificial wind on growth and transpiration in Helianthus annuus. Plant Physiol. 10:613-636.

Mitchell, C.A., H.C. Dostal, and T.M. Seipel. 1977. Dry weight reduction in mechanicallydwarfed tomato plants. J. Amer. Soc. Hort. Sci. 102(5):605-608.

Mitchell, C.A., C.J. Severson, J.A. Wott, and P.A. Hammer. 1975. Seismomorphogenic regulation of plant growth. J. Amer. Soc. Hort. Sci. 100(2):161-165.

Pappas, T. and C.A. Mitchell. 1985. Influence of seismic stress on photosynthetic productivity, gas exchange, and leaf diffusive resistance of Glycine max (L.) Merril cv. Wells II. Plant Physiol. 79:285-289.

Todd, G.W., D.L. Chadwick, and Sing-dao Tsai. 1972. Effect of wind on plant respiration. Physiol. Plant. 27:342-346.

Wheeler, R.M. and F.B. Salisbury. 1979. Water spray as a convenient means of imparting mechanical stimulation to plants. HortScience 14(3):270-271. 